\title{
Language and Context in Inter-Cultural Communication
}

\author{
Dr. Ibrahim Abushihab
}

Associate Prof. English Department

Alzaytoonah University of Jordan

\begin{abstract}
The text is considered as a final product which exists in the mind as the result of a mental activity. It is a unit of human action, interaction, communication and cognition which are based on the context. Background knowledge of the social context and its cultural norms and the power of contextual inference help in finding the particular meaning of the text. Context is an idealized abstraction of the required meaning from the communicative situation whereas contextualization, as defined by Brelsford and Rogers (2008:1) is "international effort to extend learning beyond the classroom into relevant contexts in the real world, and it also entails bringing realities of those extra academic comments into the classroom". Students who belong to a different culture often find themselves out of touch with the content of the topic being taught. Context and contextualization are essential in solving such issues.
\end{abstract}

\section{Council for Innovative Research}

Peer Review Research Publishing System

\section{Journal: Journal of Advances in Linguistics}

Vol 4, No. 2

editor@cirjal.com

www.cirjal.com 


\section{Introduction}

Communication is the exchange of ideas between two or more people. All forms of communication can be classified as verbal or non-verbal. Nankane (2003:17) states that non-verbal communication can convey multi-meanings such as "impressions, attitudes, emotions and intentions with illocutionary force". The communicative aspect of language goes beyond the components of the language: phonetics, semantics, morphology and syntax. Hartas (2005:1) also emphasizes this point, when he states that "pragmatics, or the communicative aspect of language, goes beyond the structural aspect of language, i.e. phonetics, syntax, grammar, to include knowledge of the social context and its cultural norms and an understanding of the conversational partner's intentions and needs". It is not easy to get the accurate intention of the producer of the text in a vacuum out of the context. Sell (2000:30) says "Literally texts do not communicate the observations, ideas, feelings or wishes of authors to readers, but are imaginative creations within which descriptions of things, persons and events are strictly objectified with little surrounding penumbra of that real world in which authors and readers actually live and become emotionally involved". This is illustrated by the following examples taken from Widdowson (1978:29):
A- What time is it?
B- Well, the postman's been already.

The dialogue is incoherent out of the context, but if $A$ and $B$ are sharing the same knowledge, the dialogue becomes coherent. This leads us to assume that the postman comes on specific time and B provides an answer to the question asked.

The importance of the context in interpreting the text is also obvious in this example:
A- That's the telephone.
B- I'm in the bath.
C- O.K (Widdowson, 1978:29).

B's reply to A's question is simply negative, so linguistic texts can be interpreted in connection with the assumption of the context.

So far, we can ascertain that the effective communicators need to be aware of the cultural aspects, social and cultural norms of the society where they communicate with each other. Teachers of foreign languages ought to take this fact into consideration and focus on not only teaching linguistic knowledge but also on the communicative aspect of language. Hartas (2005:8) views language as "a socially shared code, a set of arbitrary symbols and rules that govern the combination of these symbols which are used to convey ideas, thought, emotion and intentions. These symbols and their combinations are loaded with meaning shared by a community with certain social and cultural norms and conventions".

To conclude, effective communication among people requires a good knowledge of the conventions, and values of the communicative context as well as social knowledge. Andrews (2003:5) remarks that "each culture defines a model of itself based on phenomena related to that specific culture".

To fully understand a message both its connotative meaning and the context in which it has been given are essential.The following example supports this assumption:

Find the Ball. Win a house, P.4 (Brown and Yule, 1989:224).

The literal meaning of the above extract does not convey the message. But in connection with the context where it is said, we can guess that on P.4 of the newspaper, there will be a competition with task determined by the first sentence and the prize detailed in the second. Hence, Beaugrande and Dressler (1986) stress the importance of studying language in context, and not in isolated sentences.

\section{Textuality and Text Processing}

Text refers to any passage, spoken or written, regardless of its length; it is any unit of language in use. Halliday and Hassan (1976:6) point out that "a text is best regarded as a semantic unit: a unit not of form but of meaning". Text has a texture which is provided by the cohesive relation of its events. Brown and Yule (1989:190) define a text as "the verbal record of a communicative event". Beaugrande and Dressler (1986:3-10) consider a text as a communicative occurrence, which meets seven standards of textuality:

a. "Cohesion" referring to the surface text, i.e. grammatical dependencies in the surface text.

b. "Coherence" referring to the textual world, i.e. the configuration of concepts and relations which underlie the surface text.

c. "Intentionality" referring to the text writer's attitude.

d. "Acceptability" referring to the text reader's attitude towards the text.

e. "Informativity" referring to the extent to which the message of the text is (un) expected, (un) known, etc...

f. "Situationality" referring to the factors that make a text relevant to a situation. 
g. "intertextuality" referring to the factors which make the utilization of one text dependent upon knowledge of previously encountered texts.

Beaugrande and Dressler (ibid) state that the text receiver must be motivated in finding out what the text signifies, why it is selected and how it can be integrated back to the continuity that is the basis of communication as the following example shows:

"call us before you dig, you may not be able to call afterwards" (Beaugrande and Dressler, 1986:8).

This assertion that "you may not be able to call" is much more unexpected than it is in "call us before you dig".

There might be an underground cable if you break the cable, you will not have phone service and you may get a severe electric shock. Then you will not be able to call us.

Halliday and Hassan (1989) point out that text is made up of meanings far from being merely an extension of the grammatical theory. It is a product, an output, a process of semantic choice, an interactive event, and a social exchange of meanings, in addition to the analysis of how sentences and paragraphs are joined together to form larger texts, i.e., texture. The final product of the text should exist in the mind as the result of a careful mental process. A learner can perceive the texts he encounters easily if they are included in his knowledge of the world and he ought to bridge the coming texts with cultural and social aspects. van Dijk (1985) adds that the organization of language users can be seen as having intertextual, intratextual, and extratextual dimensions. Intertextuality refers to the relation between what we actually find in a text and what might have been there in its context. Intratextually refers to the relation between given pieces of a single text; and extratextually refers to the connection between a text and its world and culture.

Continuity of senses and the configuration of concepts, ideas and relations are based on culture and society. Accordingly, Beaugrande and Dressler (1986) say that there are two types of coherence: text coherence and mental coherence. Text coherence is created by means of formal and visible linguistic elements; whereas mental coherence is a mental phenomenon based on prior knowledge and context

\section{Context and Contextualization}

The speaker's knowledge about the rules of the language is considered as linguistic competence because such knowledge focuses on the linguistic aspects of the language; whereas the speaker's ability to use language socially and contextually is called conversational or communicative competence. Repley and Barrett (2008:9) state that "the components of effective communication are receptive language, expressive language, and how we use our language: pragmatics". In order to communicate effectively, people should be communicatively competent in different aspects of language. Johnson and Johnson (1999:62-65) argue that there are four major components of communicative competence: grammatical competence, sociolinguistic competence, discourse competence and strategic competence. Grammatical competence is based on knowledge of vocabulary, rules of words and sentence formation, linguistics, semantics, pronunciation and spelling. Sociolinguistic competence includes rules of appropriateness of both meanings and grammatical forms in different sociolinguistic contexts. Discourse competence includes the knowledge required to combine forms and meanings to achieve coherent spoken and written texts.Crystal (1992:78) defines context as "specific parts of a text near or adjacent to a unit which is the focus of attention. The occurrence of a unit (e.g. a sound,a word) is partly or wholly determined by its context, which is specified in terms of the unit's relations". Context requires building situations and conditions into the text. This is important to the interpretation of the text.

Contextualization is defined by Mashoko (2005:12) as " a need to understand the cultural plurality of the community and present the text in a way that can be understood according to the forms and symbols of this community". This means that the contexts, circumstances and situations are important to the interpretation of the text. Some sentences will sound ambiguous if they are read out of the context as the following example shows:

John killed the girl with a gun.

If one reads the above sentence out of the context, he would not know whether it means "John killed the girl by a gun" or "a girl with a gun was killed by John". Edmondson (1999:2) states that "contextualization, being a process, requires a suitable task for ready demonstration. For example, standard ambiguous or underspecified sentences, such as "The man saw the boy on the hill with the telescope", prompt hearers to construct and refer to situations which make senses of the sentence - a process which can be considered as contextualization". Context is considered as a setting; whereas contextualization as a process of inference.

Context and inference are related and interrelated and both are essential for human communication as in the following example:

\section{A- How about dinner this day? \\ B- I have a jealous wife.}

We can say B's reply is considered as a negative answer to the offer, because B's wife is jealous and she may prevent her husband from attending the dinner or she may spoil it. We infer from the dialogue the context which may occur during dinner. Eating dinner together is an intimate act and the jealous wife may spoil the meeting as a result of her jealousy towards other beautiful wives and girls who attend the meeting. It can be inferred that she does not like to communicate with the other women who may be attending the dinner in the presence of her husband. 


\section{Pragmatic Comprehension and Communication}

Pragmatics deals with principles of language use, the interaction of the speaker, the hearer, the writer and the reader, time, and the context of the text. The pragmatic theory is based on the speech act theory and the analysis of conversations and cultural differences in verbal interaction. Sadock and Zwicky (1985:194) add that the pragmatic theory is powerful enough to include non- grammatical accounts of the communicative effect of even the most basic sentence types. Pragmatic techniques can handle almost all the utterances we use in contexts. Sell (2000) also emphasizes the importance of pragmatics in interpreting texts. He points out that "in linguistics many of the most important developments are in pragmatics, now seen as very much including matters of intentions, meaning and value" (P.5). pragmatics is the communicative aspect of language that takes into consideration the receiver's needs and the knowledge of a conversational topic, in addition to pragmatic knowledge. Hartas (2005:10) remarks that "using and understanding figurative language, as well as reading clues in a social setting requires good pragmatic skills".

Replay and Barrett (2008:19) emphasize that the use of figurative language, such as metaphor, simile, analogy, parable and idioms can all be quite confusing for students who have limited vocabulary and not sufficient understanding of the cultural norms. Pragmatics as a communicative aspect of language goes beyond the knowledge of the components and structural aspects of language (phonetics, syntax, grammar, semantics and morphology). Austin (1962) suggests that in uttering a sentence, a speaker is generally involved in there different speech acts. First, there is the locutionary act, the act of uttering a sentence with a certain meaning as in:

"There are four bulls in that field".

In addition to that the speaker may have intended his utterance to constitute an act of praise, criticism, agreement, frightening, boasting, etc. They are all understood in accordance with their contexts. This is called illocutionary act. According to the context, the example stated above may be used for warning a walker who is about to cross the fence or as a statement to a fellow farmer or a threat to a boy who is not behaving himself. That is to say it is difficult to define the illocutionary act without knowing the context. The perlocutionary act is the real effect on the audience or receiver.Then language is not used solely to produce texts in order to convey the required message, and it is also not necessary for the form of the language to be related directly to its function, as in following example:

Teacher to his class: I see someone playing! Are you there, Ali? Class time! Where do these books belong to? It's five past eight, Sami!

Though the above examples have different forms, the directive function remains the same. The teacher wants to give orders and instructions as saying, stop playing in the classroom; come Ali and help me in cleaning the board; it is time for the lecture; put your books in their places; we start the lecture; we are late. The intention of the speaker should be understood to interpret the text.

Kempson (1977:51) describes the mechanism of a speech act as follows: the producer of a text utters it with a particular force (illocutionary act) so as to achieve a certain effect on the hearer (perlocutionary act). Accordingly, it is essential to emphasize that most speech acts are performed successfully by the recipient (hearer, reader) when he understands the producer's intentions (speaker, writer), otherwise he will fail to get the correct message and there will be a breakdown in the communication. What makes it difficult to get the intentions of the producer is the fact that some acts are expressed indirectly as in the following example:

"Do you know that my last cigarette disappeared for a long time?"

The hearer ought to find the intention of the speaker to respond to the question appropriately. The speaker does not ask a question. In fact, the utterance is a request. He asks for a cigarette. Thus, we conclude that there is no direct correspondence between speech acts and sentence types.

\section{General Pedagogical Implication}

Context and contextualization are areas of interest to linguists and educationalists. Their applications to education have gained essential focus. Ladson - Billings (1995) suggests that linking school culture with home culture and incorporating culturally relevant teaching skills are important for students to be successful learners. The importance of the context inside the classroom is due to the fact that culture and context may play an important role in facilitating learning. Teachers of foreign languages need to enrich their learners' background in the foreign language culture. This can be achieved by increasing the learners' exposure to the target language through relevant activities and exercises. The curriculum ought to be rich in such activities. In his turn, the teacher ought to provide learners with a rich learning environment free from tension. In this respect, Brelsford and Rogers (2008) state that contextualized education attempts to broaden learning beyond the cognitive understanding and to make intentional and intelligent use of specific contexts as sites of learning as teaching. Lee (2012:13) assures that "the effective attitudes and actions of teachers ultimately can make a positive difference on the lives of their students. Teachers have molded, shaped and influenced the lives of children either positively or negatively. These school experiences may last a lifetime in students' minds and can play a consequential role with present and future decisions".

In order to facilitate learning redundant in the classroom, the teacher may divide the class into discussion groups of their own selection. The students in each group reflect on the differences between the target culture and their own. The teacher may offer different topics for discussion such as national stereotype, education system ,holidays, jobs, etc, and ask them to differentiate between the two cultures. The teacher may also implement the problem- solving strategy by 
using themes from learners' everyday lives which are based on the target culture to initiate a critical dialogue. The topics may express contradictions for the students to deal with.

\section{Conclusion}

Pragmatics deals with the principles of language use, the interactions of the speaker, the writer, the reader and the hearer and the contexts of utterances (written or spoken). Van Dijk (1977:160) points out that the mode of interpretation used in pragmatics is very similar in idea to the semantic interpretation of a discourse based on a context. Pragmatic theory divides the speech acts into locutionary acts (complete act consisting of several orders of actions), illocutionary acts (communicative acts with purpose) and perlocutionary acts (consequence of illocutionary act) (Austin, 1962; van Dijk, 1977).

Context and contextualization are related; both of them are essential in teaching foreign languages. The context as defined by Johnson -Laird (1983) is the set of premises used in interpreting an utterance, it is a psychological construct, a subset of the hearer's assumptions about the world. In contrast, contextualization refers to the use of language and discourse to relevant aspects of an international communicative situation. The context is the setting in which language is used whereas contextualization is a process of acting.

\section{References}

Andrews, Edna (2003) Conversations with Lotman: Cultural Semiotics in Language, Literature and Cognitive, Toronto: University of Toronto.

Austin, John (1962) How to Do Things with Words, London: Oxford.

Beaugrande, R. and Wolfgrand Dressler (1986) Introduction to Text Linguistics, London: Longman.

Brelsford, T. and Alice Rogers P. (Ed) (2008) Contextualizing Theological Education, Cleveland: The Pilgrim Press.

Brown, Gillian and George Yule (1989) Discourse Analysis, Combridge: Combridge University Press.

Crystal, D (1992) A Dictionary of Linguistics and Phonetics, Oxford: Blackwell publishers.

Edmondon, William H. (1999) Context and Contextualization, Cognitive Science Research Centre, The University of Birmingham.

Halliday, M and R. Hassan (1976) Cohesion in English, London: Longman.

Halliday, M. and R. Hassan (1989) Language, Context and Text, London: OUP.

Hartas, Dimitra (2005) Language and Communication Difficulties, London: Continuum.

Johnson - Laird, P.N. (1983) Mental Modals: Towards a Congnitive Science of Language, Inference and Consciousness, Cambridge: CUP.

Johnson, K. and H. Johnson (1999) Encyclopedia Dictionary of Applied Linguistics, Oxford: Blackweel publishers Ltd.

Kempson, R.M. (1977) Semantic Theory, Combridge: CUP.

Ladson - Billings, G (1995) But that's just Good Teaching! The Case for Culturally Relevant Pedagogy, Theory into practice, 34, $159-165$.

Lee, Heekap (2012) Contextualized Pedagogy: New Educational Approach in the Postmodern Era, The journal of Multiculturalism in Education, Vol. 8.

Mashoko, Fennuel (2005) The Need for Contextualization in Inter- Cultural Communication of the Gospel, Master of Theology, University of South Africa.

Nankane, L (2003) Silence in Japanese-Australian Classroom Interaction: Receptions and performance, University of Sydney, Sydney.

Ripley, Kate and Jenny Barrett (2008) Supporting Speech, Language and Communication Needs, London: Sage Publications.

Sadock, J.M. Zwicky A.M.(1985) Speech Acts Distinctions in Syntax in Shopen, T. (ed.) Language Typology and Syntactic Description: Clause Structures, Combridge: CUP.

Sell, Roger D. (2000) Literature as Communication: Foundations of Mediating Criticism, Amsterdam: John Benjamins Publisher.

van Dick, T. (1985) A Handbook of Discourse Analysis, vol 1, New York: Academic Press.

van Dijk, T.A. (1977) Text and Context: Exploration in the Semantics and Pragmatics of Discourse, London: Longman.

Widdowson, H.G. (1978) Teaching Language as Communication, London: Oxford University Press. 